\title{
Towards Integrated Governance of Landscape Development
}

Author(s): Jean-David Gerber and Peter Knoepfel

Source: Mountain Research and Development, 28(2):110-115. 2008.

Published By: International Mountain Society

DOI: http://dx.doi.org/10.1659/mrd.0938

URL: http://www.bioone.org/doi/full/10.1659/mrd.0938

BioOne (www.bioone.org) is a nonprofit, online aggregation of core research in the biological, ecological, and environmental sciences. BioOne provides a sustainable online platform for over 170 journals and books published by nonprofit societies, associations, museums, institutions, and presses.

Your use of this PDF, the BioOne Web site, and all posted and associated content indicates your acceptance of BioOne's Terms of Use, available at www.bioone.org/page/terms_of_use.

Usage of BioOne content is strictly limited to personal, educational, and non-commercial use. Commercial inquiries or rights and permissions requests should be directed to the individual publisher as copyright holder. 
Jean-David Gerber

Peter Knoepfel

\section{Towards Integrated Governance of Landscape Development}

\author{
The Swiss Model of Regional Nature Parks
}

Coherent regulation of landscape as a resource is a major challenge. How can the development interests of some actors (eg cable car operators and property developers) be reconciled with those of others (agriculture, forestry) and with conservation of biodiversity and scenic value? To help understand how the newly introduced Regional Nature Parks (RNPs) can improve the coherence of the regulation regime in Switzerland, we highlight current direct mechanisms for regulation of landscape as a resource (bans, invento- ries, subsidies) as well as indirect mechanisms (taking place through the regulation of the physical basis of landscapes, eg forest, land, and water planning policies). We show that RNPs are fundamentally innovative because they make it possible to manage and coordinate indirect strategies for appropriate regulation of resources at a landscape scale. In other words, RNPs enable organization of governance of landscape as a resource in a perimeter that is not necessarily restricted to administrative boundaries.

\section{Regional Nature Parks: a new instrument in Swiss nature conservation legislation}

There is often significant overlap and potential rivalry between the ways in which a landscape as a whole might be used by various actors and the way the same or other actors use the physical elements constituting the landscape. Apart from being a material resource used by farmers for their livestock or crop production, mountain pastures also provide space for leisure activities, such as the enjoyment of nature or the quest for places with great biodiversity. Because of its non-material dimension, landscape as a resource is difficult to grasp through standard policy concepts. In Switzerland, the new instrument of Regional Nature Parks may change this.

Regional Nature Parks (RNP) were introduced as a new instrument in legislation in December 2007. RNPs aim at "conserving and developing the quality of nature and landscapes," while "reinforcing economic activities, based on sustainable development" (translation by the authors; Box 1).

The present article examines the potential of RNPs by comparison with landscape regulation strategies as they have been pursued up until now in Switzerland. It presents the regulation mechanisms of landscape as a resource in terms of public policy analysis. We highlight the direct and above all the indirect regulation mechanisms of landscape as a resource. The results stem from a research project carried out in the Swiss Alps, aiming at understanding the contribution of collective management structures to a
Definition of Regional Nature Parks (RNPs)

The revision of the 1966 Federal Law on the Protection of Nature and Landscape, which introduced the instrument of Regional Nature Parks (Art. 23g), came into force in Switzerland in December 2007. According to the law, "a regional nature park is a vast and less urbanized territory that distinguishes itself by a rich natural and cultural heritage and where buildings and infrastructures are well integrated in the rural landscape and in the appearance of localities. It aims at (a) conserving and developing the quality of nature and landscapes, (b) reinforcing economic qualities, based on sustainable development, which are carried out in its territory, and fostering the marketing of goods and services that they produce."

(Translation by the authors)

more integrated regulation of landscapes. Our research addressed the question of the practical regulation of use rights to landscapes in the context of 6 detailed case studies carried out in the Swiss Alpsin the Aletsch region in the Canton of Valais (Figure 1), the Baltschieder valley located next to the Aletsch region, the vineyard of Lavaux as a non-Alpine region, Sent-Ramosch-Tschlin in the Engadine, and the Val Bavona in the Canton of Ticino. Although we describe the Swiss situation, the regulation mechanisms result more from the specificities of the resource than from the national context, so that our conclusions go beyond the mere Swiss setting.

In order to clarify the role of regulation in the complex use situations of land- 
FIGURE 1 Landscape appropriation through strategic plots of land. The cable car company of the commune of Bettmeralp owns the panoramic restaurant on the top of the Bettmerhorn. Its exclusive control of this strategic plot of land allows this company to "sell" the Aletsch landscape to the tourists who use these facilities. (Photo by Jean-David Gerber)

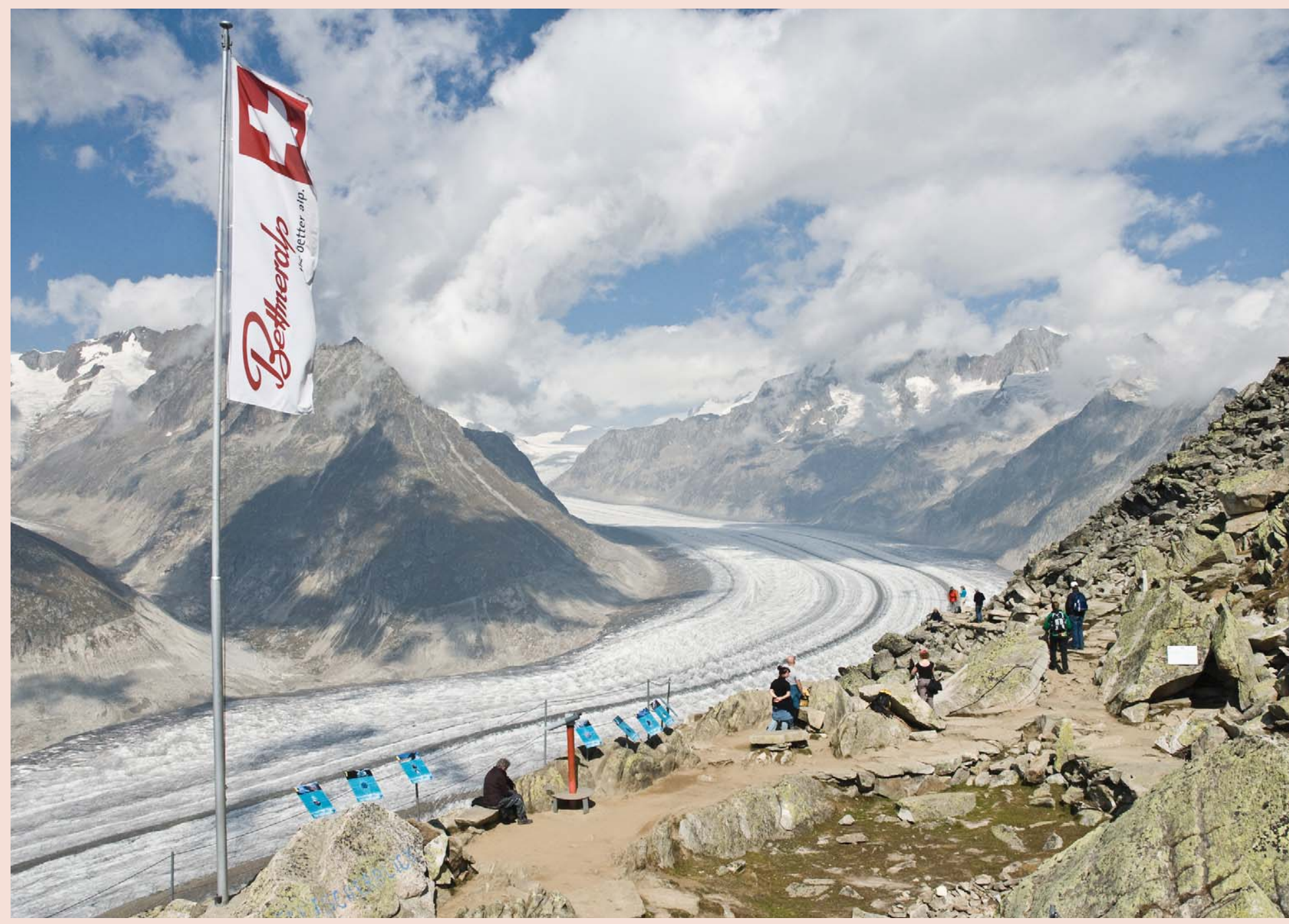

scapes, we make a clear distinction between landscape as a resource, which is cultural and non-material, and its constitutive physical elements, which we call "fundamental resources" (water, soil, fauna, buildings, etc). This approach avoids the pitfall of considering landscape as a "super-resource" incorporating all others-which creates irresolvable analytical difficulties because all policies with a spatial impact would have to be considered as landscape policies.

Among the different regulation mechanisms of landscape uses, indirect appropriation mechanisms (control of access to landscapes, possession of strategic plots of land, intellectual property, and labels associated with landscapes, etc) play a decisive role which landscape policies have not yet been able to control and coordinate. The RNP instrument is fundamentally innovative because it allows managing and coordinating these appropriation phenomena at a landscape scale.

\section{The regulation of landscapes}

The regulation of a resource can take 2 forms, which legal scholars have long conceptualized separately. On the one hand, there are sectoral public policies (the domain of public law). These policies define the general framework in which state action takes place in order to solve a public problem. Some of these policies regulate the landscape directly (eg poli- 
TABLE 1 The 4 main means of landscape regulation in Switzerland. It is particularly important to improve coherence between such diverse regulations affecting landscapes. (Source: Gerber 2006)

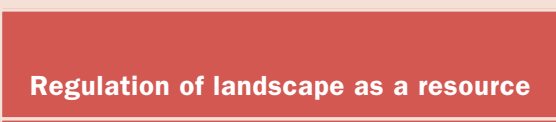

\section{Public policies}

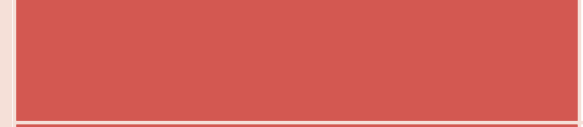

Property rights

(as written down in the land register)

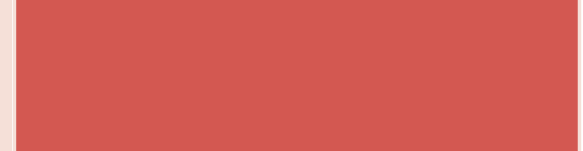

Direct:

regulation addressing landscape issues

(1) Mainly protective regulations (eg UNESCO inventories, European Landscape Convention, national/regional/local landscape legislation), as well as tourism

(3) None existing, but appropriation strategies use other means: control of strategic plots of land, regulation of access, intellectual property rights for landscape representations (labels)

\section{Indirect:}

through fundamental resources

(2) Agriculture, tourism, land use planning, infrastructure, defense, etc

(4) Land property (including accession principle ${ }^{a)}$ ), concessions on water, intellectual property rights for image/ representation of fundamental resources

a) According to established rights of access, all unmovable elements located on a plot of land (buildings, trees, etc) belong to the landowner (unless otherwise stipulated by law).

cies listing landscapes of national importance), whereas others influence it indirectly when regulating the uses of the physical basis of landscapes (Table 1). On the other hand, there are property rights (the domain of private law). In Switzerland as in other countries, room for maneuver by landowners is defined in such a way that the latter are free to use their plots of land exactly as they please as long as no public policy restricts this liberty.

Because it lacks materiality, landscape is not a "thing" in the legal sense; thus there are no formal property rights to landscape such as those that exist for its physical basis (real estate ownership, concession on water, use rights to forests). However, this does not mean that landscape users do not try to guarantee and protect their access and their future use of this resource (Table 1 ). It turns out that highlighting these indirect landscape appropriation strategies is an essential condition for a comprehensive understanding of landscape regulation issues.

\section{Landscape appropriation}

While indirect regulation of landscapes is a rather straightforward matter, landscape appropriation strategies require closer explanation. Three basic strategies can be distinguished. We exemplify them here with the help of practical situations found in our Swiss case studies.
- Strategic plots of land. The Swiss Alpine Club (SAC) owns a large number of alpine huts located in well-known landscapes. These buildings are more than landscape viewpoints. They give the SAC a position of virtual monopoly to decide about "valid" landscape viewpoints; they also allow it to decide on itineraries worth following (as the SAC is responsible for access paths). As such, these alpine huts give the SAC the possibility of fostering the mental association that observers make between a given landscape and a given alpine hut, ie between a landscape and the SAC itself. Through this process, the SAC appropriates and controls landscape representations (see Figure 1).

- Control of access. The actor who controls access to a landscape (cable car operator, main thoroughfare) can also influence the flow of visitors. He/she can increase this flow through advertising and basic marketing instruments, and try to regulate it through targeted information measures aiming at directing visitors to one or the other itinerary according to their expectations (Figure 2). In theory, he/she could also set visitor quotas. As this practice is contrary to the freedom of movement guaranteed in the Swiss Federal Constitution and the Civil Code (concerning forests and pastures), indirect means must be used: the price of the transport ticket, for example, is nothing else than 
FIGURE 2 Landscape appropriation through control of access. A food-store chain organizes the marking and signposting of mountain bike trails in the Aletsch region. They thus decide which paths are worth visiting for recreation and sightseeing. (Photo by Jean-David Gerber)

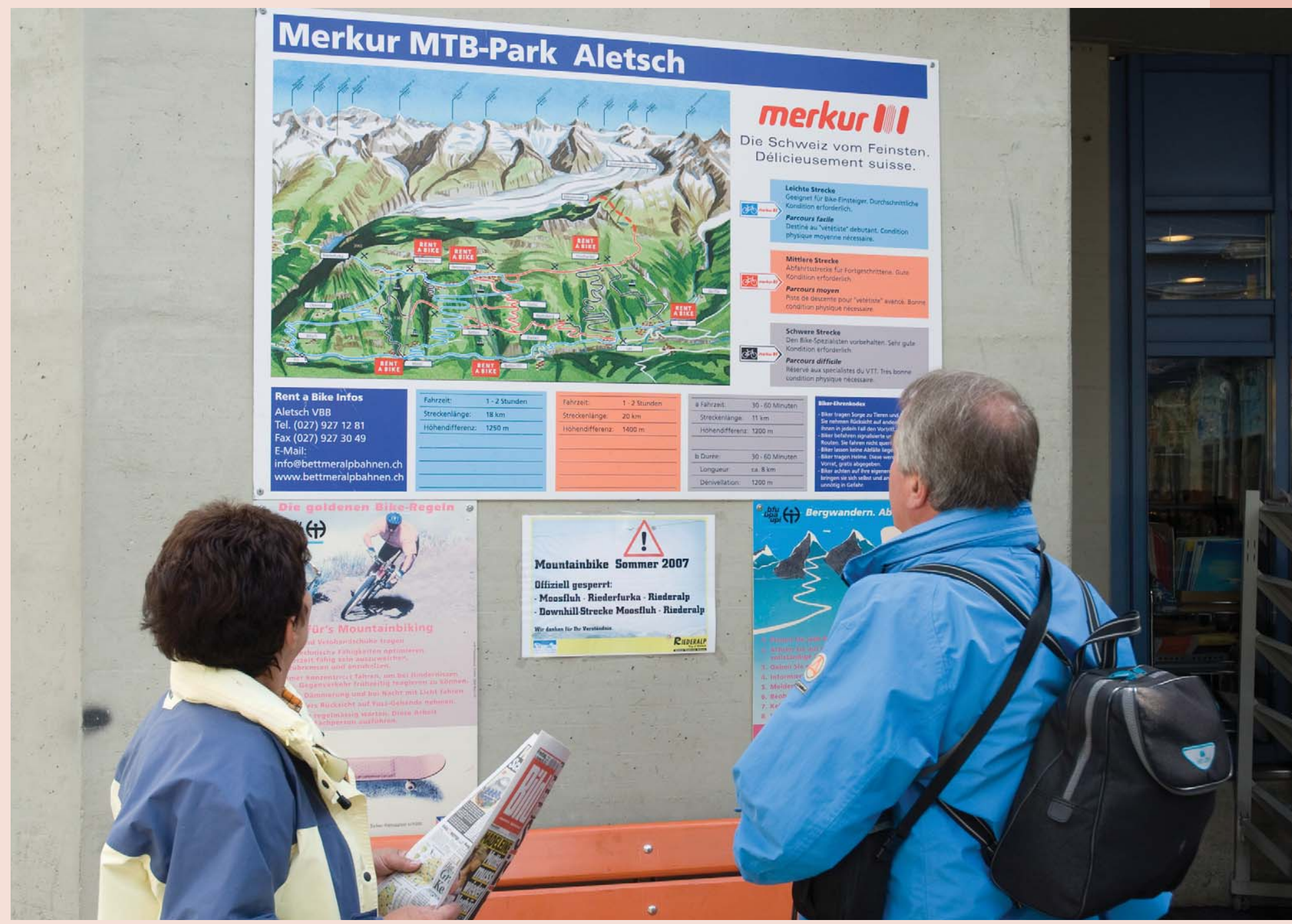

a means-which remains approximate because it is not optimized for that purpose-to put a price on landscapes and impose quotas on visitors.

- Intellectual property is also a way of appropriating landscapes. Every tourist resort tries to associate its name with a specific landscape representation that can be recognized in advertisements. As such, these representations of landscapes are protected by copyright. The issue at stake becomes all the more conflictive if the landscape in question is very well known, like the village of Riederalp with the UNESCO site of the Aletsch Glacier (Figure 3), Zermatt with the Matterhorn, Chexbres with the new UNESCO site of the Lavaux vineyards, and others). Guidebooks and roadmaps are another way of appropriating landscapes through intellectual property. When a guidebook gives a good mark to a given site in order to account for its particular beauty, or when a "panoramic road" is colored green on a map, the authors take decisions on the quality of landscapes. The positive or negative economic consequences of that act, depending on inclusion or exclusion, can be very perceptible for the villages concerned.

\section{Incoherent landscape regimes}

This brief overview of the means to regulate landscape indirectly through the regulation of their physical basis (public policies and property rights), or directly by 


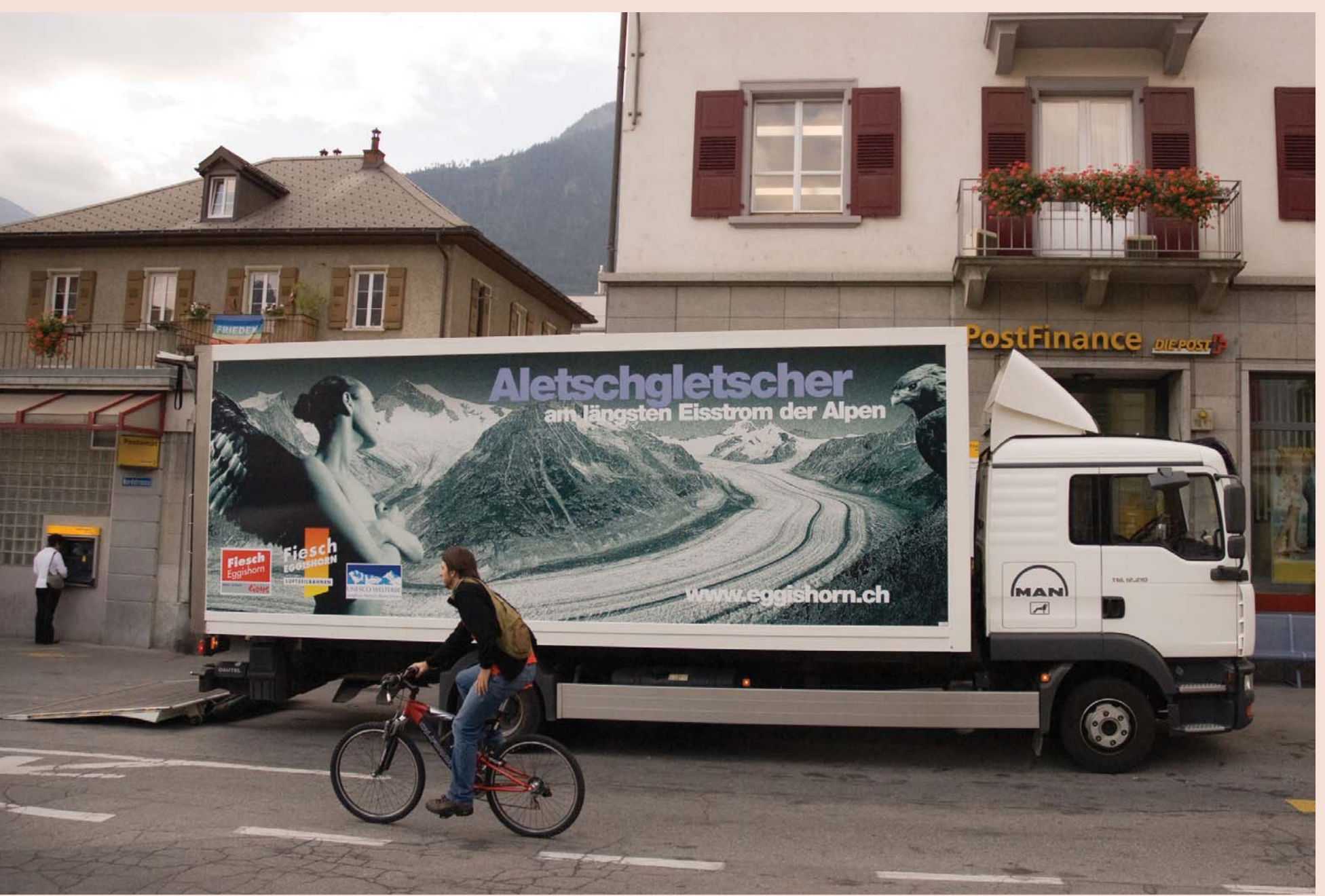

FIGURE 3 Landscape appropriation through intellectual property: the cable car company operating in the Commune of Fiesch uses the image of the Aletsch

Glacier to maintain its market position. (Photo by Jean-David Gerber) means of landscape policies and regulation of strategies for landscape appropriation by public or private actors, clearly shows how complex and varied the sources of resource regulation are when considering landscape as a resource. Thus we can expect incoherencies.

Our case studies demonstrate indeed that such incoherencies are frequent in every case where no explicit device exists aimed at counterbalancing this lack of coherence. For example, without the clear role given to the nature conservation organization Pro Natura, the Aletsch forest-a vital part of the Jungfrau-

Aletsch-Bietschhorn UNESCO World Heritage Site-would be overused by visitors. In other words, the complexity of the regulation regime leads to situations where opposite incentives, stemming from non-coordinated public policies or property rights, generate conflicts between actors that are detrimental for the quality of landscape as a resource. Indeed, in an incoherent regulation regime, user actors with opposing interests all mobilize legal norms that are not necessarily compatible with one another in order to defend their interests. In this context, the central question is to find out which regulation device is capable of improving the coherence of the landscape regulation regime and thus guarantee better coordination of the actors and their interests.

\section{RNPs for improving the coherence of regulation regimes}

The RNP represents a radical novelty in Swiss landscape policy, even though many countries have had similar instruments for 
a long time already. RNPs embody such great change for the following reasons:

The objective of RNPs is to reconcile the interests of economic development with those of landscape protection. Thus they aim explicitly at improving the coherence between use and protection policies. They can help gather the different categories of actors around the same negotiating table.

RNPs embody an approach that is oriented towards the resource as a whole rather than towards sectoral uses. Landscape is understood as a functional unit which is - at least partly-independent of single local authorities' borders. Only a resource-based approach makes it possible to account for all the specificities of a landscape and to find coherent solutions at the scale of this resource.

RNPs can be considered the rural equivalent of agglomeration policies, which also aim at solving at a supra-communal scale the coherence problem that local communities are facing in an urban environment. They allow for organizing governance of landscapes as a resource, which in general terms concerns the regulation of "the interactions among structures, processes and traditions that determine how power and responsibilities are exercised, how decisions are taken, and how citizens or other stakeholders have their say" (Graham et al 2003).

The implicit objective of RNPs, which is to intervene in the governance of a resource, is extremely ambitious and must be dealt with as such. Indeed, this implies not only influencing the behavior of landscape users, but also that of those users of the physical basis of landscape who affect it indirectly (including farmers, local developers, the tourism industry, etc). However, the creation of a new RNP does not suddenly remove asymmetries in the allocation of policy resources of the concerned actors in terms of property rights, political support, time available for negotiation, money, information, consensus, etc. Thus, a restructuring of the governance of affected landscapes requires RNPs to be sufficiently endowed with strategic resources in order to be able to create solid governance structures. The lessons drawn from the case studies lead us to highlight 3 aspects, all of which must be considered in RNP regulation regimes.

In order to be able to implement decisions that may modify the balance of power relations, RNPs must have true democratic legitimacy among the owners of legitimate use rights to landscape. This means that representatives of the population of the concerned local authorities must have a seat in the organs of the RNP. However, many of these users are mainly non-local inhabitants (city dwellers looking for preserved landscapes, nature lovers, tourists, etc). The way to integrate these actors in the decision-making process must be thoroughly thought out, because failure to integrate them puts the RNPs at risk of poorly representing the actual users of the resource.

In order to guarantee that the parks will be able to build adequate structures for landscape governance and improve the coherence of the regulation regime, RNPs must become the focal point of the main policies that have an impact on landscapes, in particular land use planning policy (eg conception of master plans). They should also control the purse-strings of new regional policy (creation of added value in peripheral regions) and of agricultural policy. Such a central position should allow for improved coordination of the financial flows stemming from the central state.

It turns out that real estate ownership remains a decisive instrument for influencing land use planning. Furthermore, the control of strategic plots of land is one of the safest ways of controlling the appropriation of landscape uses. RNPs must develop their own real estate strategy enabling them to couple the tools of land use planning with decision-making about their own land. This can give them a very effective lever to influence the evolution of "their" landscapes.

The question of governance of landscapes appears to be a key issue for the future. If properly understood as new institutional arrangements - and not merely as protected perimeters-RNPs can contribute locally to improving landscape governance, thus enabling significant steps to be taken towards more sustainable use of this resource.

\section{FURTHER READING}

Berque A. 1990. Médiance, de milieux en paysages. Montpellier, France: Reclus.

Cosgrove D. 2002. Landscape and the European sense of sight: Eyeing nature. In: Anderson K, Domosh M, Pile S, Thrift N, editors. Handbook of Cultural Geography. London, United Kingdom: SAGE Publications, pp 249-268.

Gerber J-D. 2006. Structures de gestion des rivalités d'usage du paysage: une analyse comparée de trois cas alpins. Zurich, Switzerland: Rüegger. Graham J, Amos B, Plumptre T. 2003. Governance Principles for Protected Areas in the 21st Century. Ottawa, Canada: Institute on Governance. Knoepfel P, Gerber J-D. 2008. Institutional Landscape Regimes. An Approach to the Resolution of Landscape Conflicts. Zurich, Switzerland: vdf.

Rodewald R, Knoepfel P, editors. 2005. Institutionelle Regime für nachhaltige Landschaftsentwicklung. Zurich, Switzerland: Rüegger.

\section{AUTHORS}

Jean-David Gerber and Peter Knoepfel University of Lausanne, Swiss Graduate School of Public Administration, 21 route de la Maladière, 1022 Chavannes-Lausanne, Switzerland. jean-david.gerber@idheap.unil.ch; peter.knoepfel@idheap.unil.ch Jean-David Gerber holds a PhD in public administration. Since January 2006 he has been a postdoc researcher at the Swiss Graduate School of Public Administration (IDHEAP), where he works for different projects on sustainable management of natural and cultural resources.

Peter Knoepfel holds a PhD in public law. He has held a full professorship at IDHEAP since 1982 and has published broadly on the theory and practice of public policy analysis-in particular environmental policy and sustainable development, cultural policy, and natural resources policy. 